\title{
High-altitude pulmonary hypertension
}

\author{
X-Q. Xu and Z-C. Jing
}

ABSTRACT: High-altitude pulmonary hypertension (HAPH) is a specific disease affecting populations that live at high elevations. The prevalence of HAPH among those residing at high altitudes needs to be further defined. Whereas reduction in nitric oxide production may be one mechanism for the development of $\mathrm{HAPH}$, the roles of endothelin-1 and prostaglandin $\mathrm{I}_{2}$ pathways in the pathogenesis of HAPH deserve further study.

Although some studies have suggested that genetic factors contribute to the pathogenesis of HAPH, data published to date are insufficient for the identification of a significant number of gene polymorphims in HAPH.

The clinical presentation of HAPH is nonspecific. Exertional dyspnoea is the most common symptom and signs related to right heart failure are common in late stages of HAPH. Echocardiography is the most useful screening tool and right heart catheterisation is the gold standard for the diagnosis of HAPH. The ideal management for HAPH is migration to lower altitudes. Phosphodiesterase 5 is an attractive drug target for the treatment of HAPH.

In addition, acetazolamide is a promising therapeutic agent for high-altitude pulmonary hypertension. To date, no evidence has confirmed whether endothelin-receptor antagonists have efficacy in the treatment of high-altitude pulmonary hypertension.

KEYWORDS: High-altitude pulmonary hypertension, hypoxia-inducible factor-1, nitric oxide, phosphodiesterase inhibitors, pulmonary vasoconstriction, right heart catheterisation

igh-altitude pulmonary hypertension (HAPH) due to chronic exposure to high altitude is a designated subset of pulmonary hypertension $(\mathrm{PH})$ according to the third clinical classification of $\mathrm{PH}$, which was approved during a conference in 2003 in Venice, Italy [1].

It is estimated that more than 140 million people live 2,500 $\mathrm{m}$ above sea level, and the number of temporary visitors to mountains is close to 40 million $[2,3]$. Due to the substantial population exposed to the effects of high altitude, HAPH has become a public health problem in mountainous regions throughout the world. There are three specific locations where high-altitude studies have recently been performed: 1) the Himalayas of Asia; 2) the Andes of South America; and 3) the Rocky Mountains of North America. The present review will focus on the epidemiology, pathophysiology, pathogenesis, clinical characteristics and treatment of $\mathrm{HAPH}$.

\section{DEFINITION}

$\mathrm{HAPH}$ is a clinical syndrome seen in adults and children residing in high-altitude regions. As chronic mountain syndrome (CMS) is characterised by severe hypoxaemia, excessive polycythaemia and marked $\mathrm{PH}$ [4], HAPH is regarded as an important subset of CMS. However, the definition and diagnostic criteria of HAPH remain somewhat vague. According to the 2003 conference on $\mathrm{PH}$, $\mathrm{HAPH}$ is classified in the third group of $\mathrm{PH}$ (table 1) [1]. Thus, right heart catheterisation is required to establish the diagnosis of $\mathrm{HAPH}(\mathrm{PH}$ is defined by a mean pulmonary artery pressure $\left(\bar{P}_{\text {pa }}\right)$ of $>25 \mathrm{mmHg}$ at rest or $>30 \mathrm{mmHg}$ with exercise) [5].

\section{EPIDEMIOLOGY}

Although HAPH is not a rare disorder in highaltitude residents and systolic pulmonary pressure can be evaluated easily, $\mathrm{PH}$ is infrequently noted in most CMS studies. As a result, the prevalence of $\mathrm{HAPH}$ among general highland residents is still unknown.

ALDASHEV et al. [6] surveyed the prevalence of HAPH in 741 high-altitude permanent inhabitants in a Kyrgyz population and in 2002 reported that ECG signs of cor pulmonale were presented in $23 \%$ of males and $6 \%$ of females $(p<0.0001)$. In total, 11 subjects (10 males and one female) from this cohort were further studied by right heart catheterisation. The $\bar{P}_{\text {pa }}$ in this subgroup was $31.6 \pm 3.9 \mathrm{mmHg}$ (range $20-64 \mathrm{mmHg}$ ). A resting $\bar{P}_{\text {pa }}$ of $>25 \mathrm{mmHg}$ was detected in eight subjects. However, all subjects had a pulmonary vascular resistance of $>200 \mathrm{dyn} \cdot \mathrm{s} \cdot \mathrm{m}^{-5}\left(\right.$ mean $\pm \mathrm{SD} 465 \pm 62 \mathrm{dyn} \cdot \mathrm{s} \cdot \mathrm{m}^{-5}$, range 283-925 dyn $\left.\cdot \mathrm{s} \cdot \mathrm{m}^{-5}\right)$.
AFFILIATIONS

Dept of Pulmonary Circulation, Shanghai Pulmonary Hospital, Tongji University, Shanghai, China.

\section{CORRESPONDENCE}

Z-C. Jing

Dept of Pulmonary Circulation, Shanghai Pulmonary Hospital Tongji University

No. 507, Zhengmin Road Shanghai 200433 China Fax: 862155662767

E-mail: jingzhicheng@gmail.com

Received:

December 172008 Accepted after revision: December 192008

STATEMENT OF INTEREST None declared. PROVENANCE Submitted article, peer reviewed. 


TABLE 1 Revised clinical classification of pulmonary
hypertension (PH)
1. Pulmonary arterial hypertension (PAH)
1.1. Idiopathic PAH
1.2. Familial PAH
1.3. Associated with PAH
1.3.1. Collagen vascular disease
1.3.2. Congenital systemic-to-pulmonary shunts
1.3.3. Portal hypertension
1.3.4. HIV infection
1.3.5. Drugs and toxins
1.3.6. Other (thyroid disorders, glycogen storage disease, Gaucher
disease, hereditary haemorrhagic telangiectasia, haemoglobinopathies,
myeloproliferative disorders, splenectomy)
1.4. Associated with significant venous or capillary involvement
1.4.1. Pulmonary veno-occlusive disease
1.4.2. Pulmonary capillary haemangiomatosis
1.5. Persistent PH of the newborn
2. PH with left heart disease
2.1. Left-sided atrial or ventricular heart disease
2.2. Left-sided valvular heart disease
3. PH associated with lung diseases and/or hypoxaemia
3.1. Chronic obstructive pulmonary disease
3.2. Interstitial lung disease
3.3. Sleep-disordered breathing
3.4. Alveolar hypoventilation disorders
3.5. Chronic exposure to high altitude
3.6. Developmental abnormalities
4. PH due to chronic thrombotic and/or embolic disease
4.1. Thromboembolic obstruction of proximal pulmonary arteries
4.2. Thromboembolic obstruction of distal pulmonary arteries
4.3. Nonthrombotic pulmonary embolism (tumour, parasites, foreign material)
Riscellaneous
Rulis

Several studies have shown a prevalence of HAPH between 5 and $18 \%$ in the population living at $\geqslant 3,200 \mathrm{~m}$ on the Altiplano in South America [7, 8]. WU and GE [9] reported that in the Qinghai Province of China HAPH is more common in children than adults and the enhanced incidence of HAPH with increasing altitude is more pronounced in children than adults. However, fewer HAPH patients were found among both children and adults in a population of Tibetan natives [9]. In contrast, a study by CHEN [10] in Tibet on 300 adult HAPH patients ( 289 males and 11 females) disclosed evidence of severe $\mathrm{PH}$ and enlargement of right or both ventricles as shown by ECG and chest radiographic examination. Furthermore, PH was found to be a common feature of high-altitude heart diseases.

\section{PATHOLOGY}

HAPH is characterised by increased pulmonary vascular resistance secondary to hypoxia-induced pulmonary vasoconstriction and vascular remodelling of pulmonary arterioles $[11,12]$. The vascular alterations involve all elements of the vessel wall and include endothelial dysfunction, extension of smooth muscle into previously non-muscular vessels and adventitial thickening $[13,14]$. Sites of hypoxic pulmonary vasoconstriction are small pulmonary arterioles and veins with a diameter of $<900 \mu \mathrm{m}$. Venous changes account for $\sim 20 \%$ of the total increase in pulmonary vascular resistance caused by hypoxia [7, 8]. The result of these changes is an increased pressure load on the right ventricle leading to reduced exercise capacity and premature death from right ventricular failure. The structural changes in the pulmonary vasculature are due, at least in part, to hypoxia-associated smooth muscle cell proliferation and, together with increased pulmonary vascular tone, represent targets for therapeutic intervention [6].

Histological examination of the pulmonary vessels in highaltitude residents who died from causes other than CMS showed persistence of the typical fetal patterns (thickened media) $[15,16]$. The fact that high altitude-induced changes of the pulmonary vasculature and right heart are reversible upon relocation to a lower altitude suggests a rapid remodelling process of the pulmonary vessels in response to changes in atmospheric oxygen content [17]. Moreover, the fact that at high altitude supplemental oxygen significantly decreases pulmonary arterial pressure $(\mathrm{Ppa})$, both in acclimatised healthy subjects and long-term high-altitude residents, also supports this remodeling concept [10, 18]. The study by LI and SUI [19] reported autopsy results of 20 adults and 100 infants from Tibet who had died of HAPH. The major findings included dilatation of the pulmonary artery trunk, atheromas and thrombosis of the pulmonary artery, and hypertrophy and dilation of the right ventricle and right atrium. Hypertrophy of both ventricles was also found in some cases. Compared with the normal agematched controls, the ratio of right to left ventricular weight of these patients was significantly greater and the weight of the right ventricle even exceeded the left ventricle in some cases. Severe medial hypertrophy of the small pulmonary arteries with crenation of the elastic laminae was the most significant histological finding in the pulmonary vasculature.

\section{PATHOPHYSIOLOGY}

Sustained alveolar hypoxia, such as that experienced by highaltitude residents, has a marked physiological impact on the pulmonary vasculature. The haemodynamic outcome (i.e. increased $P$ pa) is due to enhanced pulmonary vasoconstriction and pulmonary vascular remodelling, both of which cause reduction of the vascular lumen diameter and an increase in pulmonary vascular resistance [11, 12]. In rats exposed to hypoxia, pre-capillary vessels of a diameter of $\sim 25 \mathrm{~mm}$, which normally do not have smooth muscle cells, begin to generate from adventitial fibroblasts within $24 \mathrm{~h}$ [20]. Light microscopic examination of non-muscular arterioles after exposure to hypoxia shows that smooth muscle begins to appear by day 2 at simulated altitude, with the proportion of muscularised arterioles corresponding to the increasing $P$ pa [21, 22]. Interestingly, these previous studies show that after returning to normoxia, smooth muscle cells persisted in normally nonmuscularised arterioles, suggesting that the histological changes may persist for a very long time after chronic exposure to hypoxia. If confirmed in humans, these findings suggest that hypoxia-associated smooth muscle proliferation in originally weakly muscularised arterioles and normally non-muscular pulmonary vessels is likely to be a major pathophysiological mechanism for the development of HAPH. 


\section{PATHOGENESIS}

The biochemical mechanisms underlying the pathogenesis of $\mathrm{HAPH}$ are poorly understood, but a reduction in nitric oxide (NO) production is thought to play a role [23]. Animal studies showed that the absence of endothelial NO synthase increased susceptibility to HAPH [24]. ANAND et al. [25] demonstrated that inhaled $\mathrm{NO}$ can cause an acute decrease in $P$ pa, intrapulmonary shunting and improvement in oxygenation in high-altitude pulmonary oedema patients. The roles of endothelin-1 and prostaglandin $\mathrm{I}_{2}$ pathways in the pathogenesis of HAPH are still not well characterised.

In the pulmonary vasculature, it appears that transmembrane ion flux plays an important role in controlling the cellular processes that underlie both vasoconstriction and medial hypertrophy and hyperplasia during hypoxic exposure [26] Alteration in the transport of $\mathrm{K}^{+}$and $\mathrm{Ca}^{2+}$ through their respective ion channels modulates these processes by affecting cell volume, membrane potential, cytosolic $\mathrm{Ca}^{2+}$ concentration, gene transcription, apoptosis and cell-cycle progression. Precisely how $\mathrm{K}^{+}$and $\mathrm{Ca}^{2+}$ channels "sense" changes in oxygen tension or how their activity and expression somehow "adapt" at higher altitudes is unclear. Although pulmonary physiologists are attempting to define this mechanism, it is becoming increasingly apparent that ion channels themselves are probably not the actual oxygen sensors.

\section{GENETICS}

It is possible that individuals who develop high-altitude $\mathrm{PH}$ share common and, as yet, unidentified genes that influence the pulmonary arteriolar and/or venous response to hypoxia and the generation of smooth muscle cells from adventitial fibroblasts in weakly and non-muscularised pulmonary vessels. Previous studies have shown that Tibetan-native Chinese, compared to Han Chinese or South American high-altitude natives, have a remarkable lack of muscularisation of pulmonary arteries, and lower hypoxic pulmonary vasoconstrictive response and haemoglobin concentration [27]. This suggests that Tibetans' protection from high altitude-related illnesses might be due to genetic factors. LEÓN-VELARDE and MEjÍA [28] summarised the available data on genes known to be regulated by hypoxia-inducible factor-1 and/or by hypoxia that have been studied in populations from high-altitude regions suffering from $\mathrm{HAPH}$. Even though some alleles are more prevalent ( $G$ allele of endothelial NO synthase polymorphism Glu298Asp in Sherpas and angiotensin-converting enzyme (ACE)I allele in HAPH Kyrgyz) or less prevalent (ACE $\mathrm{D}$ allele in high-altitude Andeans) in the different high-altitude populations, data published to date are inconclusive regarding these gene polymorphisms in HAPH [28].

\section{CLINICAL PRESENTATIONS \\ Symptoms}

Polycythaemia, hypoxaemia and pulmonary arterial hypertension (PAH) are principal characteristics of CMS. It is highly intriguing that $\mathrm{PAH}$ has not been quantified as part of the proposed definition of CMS [29]. At an early stage, PH may be asymptomatic but, as the condition progresses, exertional dyspnoea becomes the most frequent presenting symptom. Moreover, fatigue, weakness, anginal chest pain, syncope and exercise intolerance are also common complaints. In addition to these symptoms of $\mathrm{PH}, \mathrm{HAPH}$ patients may also manifest common symptoms of CMS, such as headache, dizziness, insomnia, cognitive dysfunction, somnolence, slowed mental function, confusion and impaired memory [30].

\section{Physical examination}

Episodes suggestive of right heart failure with dyspnoea, cough, turgid jugular veins and peripheral oedema follow the initial symptoms within a few years in Han Chinese subjects [4, 31], but are rare in high-altitude residents in the Andes [32]. In both populations, marked cyanosis of the face and fingers, clubbing of the digits, hepatomegaly and ascites may be present in the late stage of the disease.

\section{Electrocardiogram}

Indices of right ventricular hypertrophy can be seen on ECG including changes in the mean QRS electrical axis in the frontal plane (standard leads I, II and III) exceeding $+90^{\circ}$.

\section{Pulmonary function test}

Patients with HAPH are usually more hypoxaemic than normal high-altitude residents, in part because of hypoventilation during both awake and sleep states. Compared with residents living at sea level, it has been found that both healthy residents at high altitude and patients with $\mathrm{HAPH}$ present a decreased ventilatory response to hypoxia, with the difference between those with and without HAPH not being statistically significant [33]. However, compared with healthy high-altitude residents, patients with $\mathrm{HAPH}$ present higher end-tidal carbon dioxide tension and lower end-tidal oxygen tension, suggesting a lower level of alveolar ventilation rather than a hypoxic ventilatory response in these subjects $[33,34]$. Thus, from the results of these studies, it may be concluded that a lower level of alveolar ventilation rather than a reduced peripheral chemosensitivity to hypoxia is the primary mechanism leading to hypoxaemia.

\section{Chest radiography}

Enlargement of the heart, dilatation of the pulmonary trunk and general dilatation of the small lung vessels were found on chest radiography and reported in Han Chinese and South Americans. Kearly's B lines are characteristically absent in HAPH patients [4]. These symptoms suggest that congestive right heart failure is associated with excessively elevated PAP in both populations.

\section{Echocardiography}

Echocardiography can provide both estimates of $P$ pa and an assessment of cardiac structure and function [35]. These features justify its application as the most commonly used screening tool in assessing patients with suspected $\mathrm{HAPH}$. Systolic $P$ pa is calculated by adding the estimated right atrial pressure to the pressure gradient between the right ventricle and the right atrium, RV and RA, respectively, ( $\triangle \mathrm{P}-\mathrm{RV} / \mathrm{RA})$ using the modified Bernouilli equation, as follows:

$$
\Delta \mathrm{P}-\mathrm{RV} / \mathrm{RA}=4 \mathrm{~V}^{2}
$$

where $\mathrm{V}$ is the peak velocity of the regurgitant jet across the tricuspid valve and $\Delta$ indicates change.

\section{Right heart catheterisation}

For the purposes of confirming the diagnosis, as well as excluding $\mathrm{PH}$ due to other causes, right heart catheterisation 
measure of $P$ pa is recommended [35]. Pulmonary haemodynamic measurements performed in children and young adults show persistence of elevated $P$ pa at high altitude for weeks, months or years [36]. Performance of right heart catheterisation was reported in Han Chinese subjects who developed $\mathrm{HAPH}$ after residing in Lhasa at an elevation 3,658 $\mathrm{m}$ for 11-36 yrs, as well as in Andes natives residing at an elevation of $\sim 4,300 \mathrm{~m}$ [32]. The haemodynamic data showed the $\bar{P}_{\text {pa averaged }} 45 \mathrm{mmHg}$ in Andes natives and $40 \mathrm{mmHg}$ in Han Chinese subjects. In all subjects, right atrial pressure, pulmonary artery occlusion pressure and cardiac output were normal. Although right heart catheterisation is the gold standard for the diagnosis of $\mathrm{PH}$, its use in the diagnosis of HAPH is quite limited and should be adopted more widely in the future by clinicians.

\section{TREATMENTS}

The ideal management for HAPH is migration to low altitude. However, for patients who choose to remain at high altitude, other means of reducing PH may be attempted, although their efficacy has not been fully established.

A number of treatments including oxygen supplementation, calcium channel blockers (such as nifedipine), NO inhalation, prostacyclins and endothelin-receptor antagonists, as well as phosphodiesterase inhibitors, have been demonstrated to decrease hypoxaemia, $\mathrm{PH}$ and the alveolar-arterial gradient in PAH. However, the efficacy of these treatments for $\mathrm{HAPH}$ needs to be further evaluated.

NO has vasorelaxant and antiproliferative effects that are mediated by cyclic guanosine monophosphate (cGMP). cGMP is hydrolysed by phosphodiesterases (PDEs). PDE5 is the major PDE subtype present in pulmonary vasculature and is more abundant in the lungs than in other tissues [37]. This abundance of PDE5 in the lungs provides a mechanism for relatively selective pulmonary vasodilatation with little systemic hypotension. Agents with PDE5 inhibitory activity reduce $P$ pa in animal models [38]. ALDASHEv et al. [39] studied the effects of sildenafil in $14 \mathrm{HAPH}$ patients and reported a reduction in $\bar{P}$ pa, with an improvement in 6-min walk distance and an increase in cardiac index after 3 months. Therefore, PDE5 is an attractive drug target for the treatment of HAPH. Long-term treatment with a PDE5 inhibitor, such as sildenafil, maybe a promising therapy for $\mathrm{HAPH}$.

Although endothelin-receptor antagonists have been proven to reduce $P$ pa and increase exercise capacity in patients with $\mathrm{PAH}$, their effects on exercise capacity at altitude are unknown. Recently, SEHEULT et al. [40] demonstrated that bosentan therapy initiated 5 days prior to ascent to high altitude did not improve exercise capacity or reduce systolic pulmonary arterial hypertension, and worsened arterial oxygen saturation measured by pulse oximetry during high-intensity exercise at altitude.

A number of studies have emphasised the mechanisms by which acetazolamide and angiotensin-converting enzyme inhibitors may be effective agents for the treatment of highaltitude pulmonary hypertension. RICHALET et al. [41] demonstrated that acetazolamide reduces hypoventilation, improves pulmonary circulation and decreases erythropoiesis. Its use as a chronic treatment for high-altitude pulmonary hypertension has been shown to be efficacious and safe [42]. The low cost of acetazolamide may allow for wide adoption with a considerable positive impact on public health in high-altitude regions. The study of angiotensin-converting enzyme inhibitors in the treatment of high-altitude pulmonary hypertension is still ongoing.

\section{ACKNOWLEDGEMENTS}

The authors would like to thank B. Li (Hong Kong, China) and B.D. Schreiber (Medical College of Wisconsin, Milwaukee, WI, USA) for their contribution to the manuscript.

\section{REFERENCES}

1 Simonneau G, Galiè N, Rubin LJ, et al. Clinical classification of pulmonary hypertension. J Am Coll Cardiol 2004; 43: Suppl. 12, 5S-12S.

2 Moore LG, Niermeyer S, Zamudio S. Human adaptation to high-altitude: regional and life-cycle perspectives. Am J Phys Anthropol, 1998: Suppl. 27, 25-64.

3 Ward MP, Milledge JS, West J, eds. High-Altitude Medicine and Physiology. New York, Oxford University Press, 2000.

4 Pei SX, Chen XJ, Si Ren ZB, et al. Chronic mountain sickness in Tibet. Q J Med 1989; 71: 555-574.

5 Barst RJ, McGoon M, Torbicki A, et al. Diagnosis and differential assessment of pulmonary arterial hypertension. J Am Coll Cardiol 2004; 43: Suppl. 12, 40S-47S.

6 Aldashev AA, Sarybaev AS, Sydykov AS, et al. Characterization of high-altitude pulmonary hypertension in the Kyrgyz: association with angiotensin-converting enzyme genotype. Am J Respir Crit Care Med 2002; 166: 1396-1402.

7 Hakim TS, Michel RP, Minami H, Chang HK. Site of pulmonary hypoxic vasoconstriction studied with arterial and venous occlusion. J Appl Physiol 1983; 54: 1298-1302.

8 Audi SH, Dawson CA, Rickaby DA, Linehan JH. Localization of the sites of pulmonary vasomotion by use of arterial and venous occlusion. J Appl Physiol 1991; 70: 2126-2136.

$9 \mathrm{Wu}$ TY, Ge RL. An investigation on high-altitude heart disease. Natl Med J China 1983; 63: 90-92.

10 Chen YC. An analysis of 300 cases of adult high-altitude heart disease. Zhonghua Xin Xue Guan Bing Za Zhi 1982; 10: 256-258.

11 Heath D, Williams D, Rios-Dalenz J, Calderdon M, Gosney J. Small pulmonary arterial vessels of Aymara Indians from the Bolivian Andes. Histopathology 1990; 16: 565-571.

12 Maggiorini M, Leon-Velarde F. High-altitude pulmonary hypertension: a pathophysiological entity to different diseases. Eur Respir J 2003; 22: 1019-1025.

13 Moudgil R, Michelakis ED, Archer SL. Hypoxic pulmonary vasoconstriction. J Appl Physiol 2005; 98: 390-403.

14 Durmowicz AG, Stenmark KR. Mechanisms of structural remodeling in chronic pulmonary hypertension. Pediatr Rev 1999; 20: e91-e102.

15 Arias-Stella J, Saldana M. The terminal portion of the pulmonary arterial tree in people native to high-altitude. Circulation 1963; 28: 915-925.

16 Gamboa R, Marticorena E. The ductus arteriosus in the newborn infant at high-altitude. Vasa 1972; 1: 192-195. 
17 Lizzarraga L. Soroche agudo: edema agudo del pulmon [Acute high-altitude illness: acute oedema of the lung]. An Fac Med Lima 1955; 38: 244-274.

18 Hultgren HN, Kelly J, Miller H. Effect of oxygen upon pulmonary circulation in acclimatised man at highaltitude. J Appl Physiol 1965; 20: 239-243.

19 Li JB, Sui GJ. Pathological findings in high-altitude heart disease. In: Applied High-altitude Medicine. Tibet, Tibet Press, 1984; pp. 288-305.

20 Sobin SS, Tremer HM, Hardy JD, Chiodi HP. Changes in arteriole in acute and chronic hypoxic pulmonary hypertension and recovery in rat. J Appl Physiol 1983; 55: 1445-1455.

21 Rabinovitch M, Gamble WJ, Miettinen OS, Reid L. Age and sex influence on pulmonary hypertension of chronic hypoxia and on recovery. Am J Physiol 1981; 240: H62-H72.

22 Rabinovitch M, Konstam MA, Gamble WJ, et al. Changes in pulmonary blood flow affect vascular response to chronic hypoxia in rats. Circ Res 1983; 52: 432-441.

23 Beall CM, Laskowski D, Strohl KP, et al. Pulmonary nitric oxide in mountain dwellers. Nature 2001; 414: 411-412.

24 Fagan KA, McMurtry I, Rodman DM. Nitric oxide synthase in pulmonary hypertension: lessons from knockout mice. Physiol Res 2000; 49: 539-548.

25 Anand IS, Prasad BA, Chugh SS, et al. Effects of inhaled nitric oxide and oxygen in high-altitude pulmonary edema. Circulation 1998; 98: 2441-2445.

26 Remillard CV, Yuan XJ. High-altitude pulmonary hypertension: role of $\mathrm{K}^{+}$and $\mathrm{Ca}^{2+}$ channels. High Alt Med Biol 2005; 6: 133-146.

27 Groves BM, Droma T, Sutton JR, et al. Minimal hypoxic pulmonary hypertension in normal Tibetans at 3,658 m. J Appl Physiol 1993; 74: 312-318.

28 León-Velarde F, Mejía O. Gene expression in chronic high altitude diseases. High Alt Med Biol 2008; 9: 130-139.

29 Reeves JT. Chronic mountain sickness. In: Ohno $\mathrm{H}$, Kobayashi T, Masuyama S, Nakashima M, eds. Progress in Mountain Medicine and High-altitude Physiology. Matsumoto, Japan, 1998; pp. 153-159.

30 Winslow RM, Monge CC, eds. Hypoxia, Polycythemia and Chronic Mountain Sickness. Baltimore, John Hopkins University Press, 1987; pp. 19-30.

31 Ge RL, Helun G. Current concept of chronic mountain sickness: pulmonary hypertension-related high-altitude heart disease. Wilderness Environ Med 2001; 12: 190-194.
32 Hultgren $\mathrm{H}$. Chronic mountain sickness. In: Hultgren $\mathrm{H}_{,}$ ed. High-altitude Medicine. San Francisco, Hultgren Publication, 1997; pp. 348-367.

33 Leon-Velarde F, Gamboa A, Rivera-Ch M, Palacios JA, Robbins PA. Plasticity in respiratory motor control: selected contribution. Peripheral chemoreflex function in high-altitude natives and patients with chronic mountain sickness. J Appl Physiol 2003; 94: 1269-1278.

34 Kryger M, McCullough R, Doekel R, Collins D, Weil JV, Grover RF. Excessive polycythemia of high-altitude: role of ventilatory drive and lung disease. Am Rev Respir Dis 1978; 118: 659-666.

35 McGoon M, Gutterman D, Steen V, et al. Screening, early detection, and diagnosis of pulmonary arterial hypertension: ACCP Evidence-Based Clinical Practice Guidelines. Chest 2004; 126: Suppl. 1, 14S-34S.

36 Sime F, Banchero N, Penaloza D, Gamboa R, Cruz J, Marticorena E. Pulmonary hypertension in children born and living at high-altitudes. Am J Cardiol 1963; 11: 143-149.

37 Clarke WR, Uezono S, Chambers A, Doepfner P. The type III phosphodiesterase inhibitor milrinone and type V PDE inhibitor dipyridamole individually and synergistically reduce elevated pulmonary vascular resistance. Pulm Pharmacol 1994; 7: 81-89.

38 McMahon TJ, Ignarro LJ, Kadowitz PJ. Influence of zaprinast on vascular tone and vasodilator responses in the cat pulmonary vascular bed. J Appl Physiol 1993; 74: 1704-1711.

39 Aldashev AA, Kojonazarov1 BK, Amatov TA, et al. Phosphodiesterase type 5 and high-altitude pulmonary hypertension. Thorax 2005; 60: 683-687.

40 Seheult RD, Ruh K, Foster GP, Anholm JD. Prophylactic bosentan does not improve exercise capacity or lower pulmonary artery systolic pressure at high altitude. Respir Physiol Neurobiol 2008; [Epub ahead of print PMID: 18977464].

41 Richalet JP, Rivera M, Bouchet P, et al. Acetazolamide: a treatment for chronic mountain sickness. Am J Respir Crit Care Med 2005; 172: 1427-1433.

42 Richalet JP, Rivera-Ch M, Maignan M, et al. Acetazolamide for Monge's disease: efficiency and tolerance of 6-month treatment. Am J Respir Crit Care Med 2008; 177: 1370-1376. 